\title{
The Place of Informal Logic in Philosophy
}

\section{James B. Freeman Hunter College, CUNY}

\begin{abstract}
We argue that informal logic is epistemological. Two central questions concern premise acceptability and connection adequacy. Both may be explicated in terms of justification, a central epistemological concept. That some premises are basic parallels a foundationalist account of basic beliefs and epistemic support. Some epistemological accounts of these concepts may advance the analysis of premise acceptability and connection adequacy. Informal logic has implications for other aspects of philosophy. If causal interpretations are acceptable premises and thus justified, does the world have a causal structure? If evaluative premises are acceptable, i.e., justified, is value an objective feature of the world?
\end{abstract}

Résumé: Nous soutenons que la logique non formelle est épistémologique. Ses notions centrales, l'acceptabilité et la suffisance des prémisses, peuvent s'expliquer en termes de justification, un concept fondamental en épistémologie. Les prémisses de base se comparent aux croyances de base et à l'appui épistémique qu'on trouve dans le fondationalisme. Certaines explications épistémologiques de ces concepts peuvent avancer l'analyse de l'acceptabilité et de la suffisance des prémisses. La portée de la logique non formelle s'étend à d'autres aspects de la philosophie. Si des interprétations causales sont des prémisses acceptables, donc justifiées, est-ce que le monde a une structure causale? Si des prémisses évaluatives sont acceptables, c.-à-d. justifiées, est-ce que la valeur est un trait objectif du monde?

Keywords: applied epistemology, acceptability, relevance, ground adequacy, justification, foundationalism, properly basic belief, interpretation, evaluation.

For the Third International Symposium on Informal Logic in 1989, Ralph Johnson and $\mathrm{J}$. Anthony Blair asked me to prepare a paper on the relation of informal logic to the wider logical enterprise, in particular to formal logic. The result was my paper, "The Place of Informal Logic in Logic" (Freeman, 1994). For the roundtable at the Twentieth World Congress of Philosophy, Johnson and Blair asked me to address the question of the philosophical significance of informal logic and its applications or implications for other areas of philosophy. The result is this paper, "The Place of Informal Logic in Philosophy."

Some might urge that this topic has already been addressed, for some have argued that we should regard informal logic as applied epistemology. Mark Battersby explicitly defends this thesis. He sees the discipline of critical thinking as the discipline concerned with applying epistemological norms to common problems and to 
questions of what we should believe. Thus he believes that this discipline would better be called applied epistemology rather than informal logic (Battersby, 1989). For example, in discussing how eliminating alternative causal hypotheses contributes to a proper defense of a causal claim, Battersby believes we are presenting an epistemological norm rather than a logical principle (ibid., 95). ' At the Third International Symposium on Informal Logic, Mark Weinstein argued that informal logic ideally should be a type of applied epistemology. His conception of what this entails, however, is so different from the epistemological considerations we shall consider below that we cannot comment on it further. Harvey Siegel also has long argued for the centrality of epistemological issues in informal logic. ${ }^{2}$ If informal logic is a special type or area of epistemology or closely connected with epistemology, then we have already identified its place in philosophy. Although I fully agree with the epistemological approach, I believe that we may adduce fresh reasons for seeing the epistemological questions informal logic raises as constituting its principal philosophical significance and implication. Furthermore, in the light of these reasons, we can see implications of informal logic for the other main systematic areas of philosophy, metaphysics and moral philosophy or more generally value theory. To see what these implications are, I want to first review certain salient features of informal logic.

\section{Informal Logic and the Arguments of the Polis}

The claim that informal logic is focused on the arguments of the polis seems uncontroversial. Analysing and evaluating arguments about what we should believe concerning how we may best order our lives together and what we should do as a consequence is central to the informal logic enterprise as standardly understood. This focus in itself gives informal logic a significant philosophical implication-the issues of the polis are open to reasoned consideration. We can discriminate better from worse arguments for positions on these issues.

But what sorts of issues are included in the polis? Many will be issues of interpretation and evaluation. Who is to count as a human person? Does this concept include individuals outside one's ethnic group or nationality? Does it include the unborn, those at the end of life, those whose deteriorating health has made them inconvenient to those around them? What rights-at least prima facie rightssupervene on being a person? Is it morally right to bring a human being into the world through cloning in order to use the clone's cells to remedy deficiencies in one's own body, even if the clone will be brought up in an affectionate environment? Does the emission of certain substances cause changes in the environment, changes which will cause harm to human beings and beings of other living species, and thus be bad? The issues of whether a living being is a person or whether certain conditions will have certain causal effects are questions of interpretation, while the issues of moral right, of rights, and of good or bad are issues of evaluation. 
But such statements may be the conclusions of arguments put forward in the polis. By taking such arguments as the subject matter of evaluation, informal logic already aligns itself against philosophical positions which would dismiss interpretations and evaluations as merely matters of opinion or expressions of emotion. If interpretations can be defended by cogent arguments, they are not mere opinions but justified opinions. Likewise, if an evaluation can be defended by cogent argument, it is not a mere expression of taste but exerts some claim upon our serious consideration. So the first philosophical implication of informal logic is to count the issues of the polis among those upon which persons may hold justified or justifiable points of view. Such issues are open to reasoned argument.

But how are such arguments evaluated within informal logic? Certain early informal logic texts presented significant lists of fallacies. ${ }^{3}$ However, Johnson and Blair in Logical Self Defense identified three basic fallacies-irrelevant reason, hasty conclusion, and problematic premise - which have come in the minds of many to delimit argument evaluation within informal logic. If the premises of an argument are not relevant to its conclusion, do not give sufficient support or constitute grounds adequate for accepting the conclusion, or are problematic, then there is a problem with the cogency of the argument. These conditions may be stated positively. If the premises are relevant to the conclusion, together they constitute reasons sufficient or grounds adequate to accepting the conclusion, and - if being acceptable is the opposite of being problematic-the premises are acceptable, then the argument satisfies three necessary conditions for cogency. ${ }^{4}$ Trudy Govier has given us a handy memory device for remembering these criteria in the $A R G$ acronym. For cogent argumentation, the premises of an argument must be $A$ cceptable, Relevant to the conclusion, and constitute $G$ rounds adequate for accepting it.

However, each of these criteria is philosophically problematic. Although in many cases it is intuitively clear that certain statements are uncontroversial while others involve a distinct air of controversiality and so would constitute problematic premises, explicating philosophically just what it means for a premise to be acceptable remains an open questions. Again, although some statements obviously provide evidence for some claim while others are obviously irrelevant, a criterion determining just what it means for a set of premises to be relevant to a conclusion awaits general agreement. Although it may be obvious in some cases that certain premises would constitute very flimsy and insufficient evidence for a conclusion while other premises may be telling, a general approach to assessing the ground adequacy of premises remains to be developed. We claim that unlike formal deductive logic, where such core logical concepts as validity and logical truth can be defined semantically and without significant philosophical inquiry, the conceptual analysis of acceptability, relevance, and ground adequacy is or ought to be philosophical. In particular, it is epistemological. To see this, let us consider certain basic concepts of epistemology. 


\section{Epistemological Nature of the Basic Questions}

It is a commonplace that many philosophers have maintained that knowledge is justified true belief. This analysis goes back at least as far as Plato's Theaetetus. Even after Gettier's famous counterexamples (Gettier, 1963), philosophers have tried to maintain this basic analysis, adding some further condition which hopefully will avoid the counterexample. Setting aside whatever may be the merits of these projects, they do show one thing-that there is a family of epistemic concepts and "justified," "true," and "belief" are all members of that family. Hence the philosophical analysis of these concepts may be viewed legitimately as a part of epistemology, and the concepts themselves as epistemological.

What is the import of this point? In many cases, philosophers have held what one might call a high view of knowledge. W.D. Ross expresses this view succinctly: "A statement is certain, i.e. is an expression of knowledge, only in one or other of two cases: when it is either self-evident, or a valid conclusion from selfevident premises" (Ross, 1930, 30). So a hallmark of knowledge, a necessary condition for there to be knowledge, is certainty. Ross repeats this point when he says that a "respect in which knowledge differs from and is superior to opinion is that of certainty or complete absence of doubt" (ibid., 147). Now philosophers may certainly debate whether certainty is a necessary condition for knowledge, or whether there might be at least two senses of knowledge, only one of which entails certainty. We may rather grant that certainty is necessary for knowledge, but then ask whether knowledge is a relevant standard for evaluating the discourse of the polis. Surely, under this understanding, it is not.

Suppose a jury is presented with the evidence of ten eyewitnesses who positively identify the accused as having driven and parked a van immediately outside a major public building. As forensic analysis has shown, this van was loaded with explosives whose subsequent detonation seriously damaged the building and caused significant loss of human life. On the basis of this and further pertinent evidence, the jury convicts the accused on a charge of terrorism. Was the jury's action proper? Notice that although it might be self-evident to each witness that he or she was appeared to in a certain way, it was not self-evident to the witnesses that the accused drove the van. Nor were the various causal claims about the explosion and its consequences self-evident. Nor was the claim that the accused was guilty of terrorism entailed, in a deductive or necessary sense, from these statements. That is, in the high sense of knowledge that we are considering, the jury did not know that the accused was guilty. Were they justified in rendering this conviction? Can we distinguish their action from simply wielding naked political power to marginalize or victimize the accused? The answer is obviously yes. But this shows that knowledge is not what we are after in the polis, and to judge the arguments of the polis by a knowledge criterion - the conclusions properly constitute knowledge-would be to apply a highly inappropriate yardstick. 
But our counter-example does not show that the concepts out of which philosophers have sought to construct a definition of knowledge are inappropriate yardsticks for evaluating the claims of the polis. Surely the jury's belief that the accused was guilty of terrorism was justified. And surely it was justified not just in the sense that the jury possessed or was aware of some evidence or other positively relevant to the conclusion, but in the sense that the jury possessed sufficient evidence to warrant believing this conclusion. 'Justified' then or 'justified belief' may be a perfectly appropriate criterion to apply to the discourse of the polis. We would expect the conclusions of arguments in the polis to be justified and indeed the arguments given for those conclusions to themselves supply that justification. But this would seem to presuppose that the premises of those arguments would be justified and that the arguments themselves would suffice to transfer that justification to the conclusion.

Surely it would seem that the premises of an argument would be acceptable if believing or accepting them would be justified. Surely our premises should constitute grounds adequate for accepting the conclusion if they were so related to that conclusion as to transfer their justification to it. Justification seems to be the hallmark we are looking for in judging the argumentation of the polis. But justification, as we have seen, is an epistemic or epistemological concept. The analysis of this concept is an epistemological assay.

Furthermore, it is a needed assay. To say that the premises of an argument are acceptable just in case they are justified or that an argument satisfies the ground adequacy and relevance criteria just in case it transfers the justifiedness of its premises to its conclusion is to assert a platitude in the absence of an analysis of justification. But 'justification' covers a plethora of concepts. William Alston in "Concepts of Epistemic Justification" (1965) distinguishes deontological from evaluative concepts and under those headings identifies various further concepts. He remarks that "in the absence of an explicit account of the concept being applied, we lack the most fundamental basis for deciding between supposed intuitions and for evaluating proposed conditions of justification." Will the real concept of justification please stand up? We can pose this question more precisely: When the goal of our analysis is to produce an account of acceptability in the polis, is there a concept of justification which is uniquely proper to or illuminating for this analysis?

This question goes far toward disclosing informal logic's place within philosophy. The concept of acceptability is proper to informal logic. By seeking to explicate this concept, we are investigating the theory of informal logic. But by seeking to do this by identifying a specific concept of justification, an epistemic notion, we are undertaking an epistemological investigation. Informal logic is included within epistemology or is epistemology done with a particular aim in view. To the question then of what is the place of informal logic in philosophy, we may say that informal logic - the theory of it at least-is a field within epistemology, that field 
concerned with the norms and criteria of acceptability of claims arising within the polis.

\section{Implications of Informal Logic for Epistemology}

Not only does informal logic constitute a field within epistemology, I believe it also has implications for how one does epistemology, for the approaches or positions one might take in epistemology. To illustrate, recall that it is a commonplace that any argument will have basic premises-premises which are not argued for at least within the context of that argument. This is not to say that the premises cannot be argued for. But even if they were, those arguments in turn would have basic premises. Hence if those arguments were incorporated into the original argument, the resulting argument would still have basic premises. This, of course, assumes that we are not constructing a totally circular argument in which every premise is ultimately defended in terms of itself - a fallacy. So any non-fallacious argument will go back to basic premises.

This feature of the macrostructure of arguments is obviously parallel to how foundationalism - a central epistemological tradition in modern philosophy-views the structure of our beliefs. We hold some beliefs on the basis of other beliefs constituting propositional evidence for them. Our moving from evidential beliefs to a belief the evidence warrants constitutes an inferential step. But there are some beliefs which are not inferred. We form them directly when confronted with certain non-propositional evidence. For example, when appeared to in a certain visual way, I may form a belief that there is a tree directly in front of me outside my office window. When appeared to in another, auditory, way, I may form the belief that a bus is passing on the street. These are basic beliefs. On the foundationalist account, belief structure parallels argument structure. This certainly could incline an informal logician to favor a foundationalist approach in epistemology.

The question arises: Are there resources in epistemology which will advance our understanding of issues in informal logic? We may form certain basic beliefs. But are those beliefs justified? We may take certain premises as basic in constructing an argument, but are those premises acceptable? Basic beliefs which are justified are properly basic beliefs. Plantinga proposes that we may characterize a belief as "properly basic for me if it is basic for me and I am justified, violating no epistemic duties, in accepting it in the basic way" $(1993,20 \mathrm{n})$, where "a proposition is basic for me if I accept it, but do not accept it on the evidential basis of other beliefs" (ibid., 19n). Are there any properly basic beliefs and if so, are the statements which express them properly basic premises, premises which are acceptable in themselves without defense on the basis of other statements taken as premises?

Although we cannot answer that question within the scope of this paper, ${ }^{5}$ we can point out the relevance of contrasting foundationalist views to formulating such an answer. According to classical foundationalism, beliefs are properly basic 
just in case they are self-evident. These would include such elementary propositions of mathematics and logic as ' $7+5=12$ ' or the law of non-contradiction, or propositions about how one is immediately appeared to (cf. Plantinga, 1993, 20n). If the only acceptable basic premises are those which express properly basic beliefs understood this way, then few if any arguments of the polis will have acceptable basic premises. Indeed, from this point of view, the argumentation of the polis will be based on sinking sand.

But here the distinction between knowledge and acceptability comes to the fore. Classical foundationalism is a position about the nature of knowledge and how our knowledge must ultimately be grounded, a view which is clearly aligned with the high view of knowledge we considered above. But if our goal is to explicate acceptability rather than knowledge, classical foundationalism appears to be an inappropriate position from which to carry out that assay. It would be unacceptable unless, of course, only premises which are self-evident, those premises which are properly basic on classical foundationalist grounds, are acceptable as basic premises. This is a position which the classical foundationalist would need to argue. But why should we think that the only viable sense of justification would be a sense suitable for explicating a high view of knowledge as opposed to acceptability in the polis?

Besides this, there are foundationalist alternatives to classical foundationalism. We might call one such position common sense foundationalism. It derives much inspiration from the Scottish common sense philosophy of Thomas Reid. Put briefly, on this view a proposition will be properly basic for me just in case there is a presumption from my point of view that my cognitive mechanisms which generated this belief are generally reliable and functioning properly, in a normal environment, with a view to producing true beliefs. ${ }^{6}$ So if I am appeared to in the manner of a tree outside my window, on that basis form the belief that indeed there is a tree outside my window, and I have no reason to think that my visual perceptual mechanism is faulty or undergoing unusual perturbations, then my belief that there is a tree in front of me is not only a basic belief but a properly basic belief. That this conception of proper basicality is strongly in accord with what we expect for the acceptability of basic premises in the argumentation of the polis is born out by these remarks of Reid:

By the laws of all nations, in the most solemn judicial trials, wherein men's fortunes and lives are at stake, the sentence passes according to the testimony of eye or ear witnesses of good credit. An upright judge will give a fair hearing to every objection that can be made to the integrity of a witness, and allow it to be possible that he may be corrupted; but no judge will ever suppose that witnesses may be imposed upon by trusting to their eyes and ears. And if a sceptical [sic] counsel should plead against the testimony of the witnesses, that they had no other evidence for what they declared but the testimony of their eyes and ears, and that we ought not to put so much faith in our senses as to deprive men of life of fortune upon their testimony, 
surely no upright judge would admit a plea of this kind. I believe no counsel, however sceptical, ever dared to offer such an argument; and, if it was offered, it would be rejected with disdain. (1983, 161-162)

All this suggests that we might explicate premise acceptability as proper basicality understood according to common sense foundationalism. Establishing such a claim goes far beyond the scope of this paper. But understanding how such a claim may be suggested lets us see how viewing the basic informal logic issue of premise acceptability as an epistemological issue can both direct our stance vis-a-vis the epistemological positions we take and advance our inquiry into the proper understanding of premise acceptability.

So far we have only sketched how investigating the issue of premise acceptability has implications for epistemology. What about the issues of relevance and ground adequacy, the two issues which together define the question of connection adequacy? When are the premises of an argument adequately connected to its conclusion? Here again, the parallel between argument structure and doxastic structure on a foundationalist account may direct our investigation into these issues. For epistemologists are concerned not just with proper basicality but with the support relation. When is warrant or justification transferred from one belief to another? When is a belief justified on the basis of others? This leads us directly to the notion of epistemic probability, an area of epistemology notoriously beset by difficulties.

But turning to this area when investigating connection adequacy may have positive implications for both informal logic and epistemology. First, since the epistemological area is thorny, those in informal logic should not feel embarrassed if they do not have ready answers to the question of when premises are relevant to conclusions or just when they constitute grounds adequate for accepting the conclusion. On the other hand, that we are seeking norms for connection adequacy for arguments in the polis rules out any crude deductivist account of epistemic probability. It may be that work done on analysing everyday reasoning, reasoning in the polis, which has already been noted in the informal logic community-for example, work on non-monotonic logic-will have fruitful implications for clarifying issues in epistemic probability. We cannot pursue these issues further.

So far, we have discussed the place of informal logic in epistemology and its implications for epistemology. Now if, as we have argued, informal logic is a branch of epistemology and epistemology is one of the three main divisions of philosophy, we have already delineated the place of informal logic in philosophy. But we can ask whether we can identify any direct implications of informal logic for the remaining two major systematic divisions of philosophy: metaphysics and moral philosophy. We turn to that question in the next section. 


\section{Implications of Informal Logic for Metaphysics and Moral Philosophy}

Our discussion suggests that if we analyse acceptability in terms of justification, understanding a premise's being acceptable for us just in case it expresses a belief which is justified from our point of view, then some basic premises should be acceptable for us. If I am appeared to in the manner of a tree outside my office window and $I$ have no reason to think in this case that I am suffering from some hallucination or illusion or otherwise to doubt my senses, then my belief that there is a tree outside my office window is justified. Should I take the statement that there is a tree outside my office window as a basic premise, that premise would be acceptable from my point of view. Not only then do we have an analysis of acceptability, but some basic premises at least may be acceptable. But this immediately opens up further philosophical questions. In his essay Inductive Inference and Its Natural Ground, Hilary Kornblith addresses himself principally to two questions (1993, vii, viii):

What is the world that we may know it?

What are we that we may know the world?

Our investigation prompts us to ask two parallel questions:

What is the world that we may have justified beliefs about it?

What are we that we may have justified beliefs about the world?

The first is clearly a question of metaphysics, the second of philosophy of mind.

The range of arguments informal logic considers impels us to ask these questions more deeply than our discussion heretofore suggests. The claim that there is a tree outside my office window is a simple description. Far more typical of the arguments of the polis are statements expressing evaluations or interpretations. ${ }^{7}$ One may argue that certain attitudes, those fostered by modern liberal individualsim for example, should be avoided because holding them leads to the disintegration of culture and society. Here one is arguing for an evaluation on the basis of an explicit premise which is a causal statement and thus an interpretation. May we have justified interpretive and evaluative beliefs? These are in the first instance epistemological questions. But causal statements are a paradigm case of interpretations. If we may have justified causal beliefs, may we infer that the world has a causal structure which is somehow mirrored in our causal beliefs? Can we understand the reliability of the mechanism generating causal beliefs without attributing to the world a causal structure? These are clearly central questions in metaphysics and philosophy of mind.

Obviously, philosophers will debate long and hard over these issues. We need make only two points here. First, since arguments of the polis can involve interpretations among their premises, the informal logic issue of premise acceptability requires that we ask these questions in metaphysics and philosophy of mind about the structure of the world and the nature of our minds in being able to form reliable beliefs about that structure. But secondly, if we can have justified causal (more 
generally interpretative) beliefs, does this not count for metaphysical views which attribute a genuine causal structure to the world and to our minds an ability to grasp that causal structure? If there is not a presumption for realism here, is there not at least a preference?

Turning to moral philosophy or value theory more generally, we can trace this same progression. Are any of the basic evaluative premises in any arguments of the polis ever acceptable? Do the premises of any argument in the polis ever transfer their acceptability to an evaluative conclusion? This raises the question of whether evaluative beliefs can ever be justified, a question of moral epistemology. (It may be, as C.D. Broad opines in "Some Reflections on Moral-Sense Theories in Ethics," that moral epistemology "has been very inadequately treated by most writers on ethics" $(1952,363)$. If so, then informal logic has a major implication for philosophy in bringing this area to the fore.) But we can argue that we do have justified moral beliefs. Indeed, the argument has basically been set out quite straightforwardly by W.D. Ross in The Right and the Good. He remarks, "To me it seems as self-evident as anything can be, that to make a promise... is to create a moral claim on us in somebody else" (Ross, 1930,21 n). Thus I have a prima facie duty to keep my promises and the claim that I do is self-evident, a truth of reason. Now as Ross points out, concrete situations give rise to conflicts of duties. A given action may be a prima facie duty on certain considerations. But it may be prima facie wrong on others. Whether it is actually or overridingly right is a matter of weighing one set of characteristics against another. But it would seem that if one carries out this weighing conscientiously and arrives at the conclusion that a certain action is right, then this belief is justified.

Consider a simpler example. Suppose I am aware that an action is an instance of promise keeping and thus is a prima facie duty. That belief is self-evident and thus is surely justified. But suppose I am not aware of any other morally significant feature of this action or of any reasons which would impel me to investigate the situation further to discover such features. Given this evidential context, I judge the action to be actually my duty. Surely this belief is justified. But then we may ask these analogues of Kornblith's questions:

What is the world that we may have justified evaluative beliefs concerning it?

What are we that we may have justified evaluative beliefs about the world?

The first is a question in moral philosophy and metaphysics--in the "metaphysics of morals" we might want to say. The second as before is a question in the philosophy of mind. Again, if we can have justified evaluative beliefs, does this not give a preference to theories which see value as an objective feature of the world?

Thus we see that informal logic has implications for epistemology, metaphysics, philosophy of mind, moral philosophy and value theory in general; that is, for practically the whole of philosophy. By seeking norms or criteria for judging the cogency of arguments in the polis-arguments which take issues of description, interpretation, and evaluation into account, by seeking to explicate what premise 
acceptability and connection adequacy mean vis-a-vis such arguments, informal logic raises issues in the core areas of philosophy and at least gives us a predisposition to favoring answers of a certain sort. 1 submit that in these implications we may see the place of informal logic in philosophy.

\section{Notes}

'Apparently, Battersby sees inductive issues as being part of epistemology, and not as constituting a branch of logic called induction.

${ }^{2}$ See, for example, the section "Critical Thinking and Epistemology" in Siegel, 1985.

${ }^{3}$ Kahanen (1980) presents twenty-eight, Johnson and Blair (1977) treats nineteen, Fearnside and Holther (1959), a precursor of the informal logic texts, presents fifty-one!

${ }^{4} \mathrm{We}$ are not here saying that these three conditions are jointly sufficient. To be cogent, it would seem that arguments would have to satisfy an additional preliminary condition, that their component statements, premises and conclusions, be free of expressions whose meaning is ambiguous or indeterminate. However, the three criteria of relevance, sufficiency, and acceptability have assumed a prominence in the literature.

${ }^{3}$ We discuss this issue at length in a monograph tentatively entitled Warrant, Presumption, Acceptability: A Theory of Epistemic Appraisal, in preparation.

${ }^{6}$ This concept is heavily indebted to the work of Alvin Plantinga (1993b), Chapter One and especially p. 19.' For a discussion of the description/interpretation/evaluation distinction, see Freeman, 1993, 163-67.

${ }^{8}$ I wish to thank Prof. Eric Steinhart for comments on an earlier version of this paper.

\section{References}

Alston, William P. (1965). "Concepts of Epistemic Justification." Monist, 68. p. 57.

Battersby, Mark E. (1989). "Critical Thinking as Applied Epistemology: Relocating Critical Thinking in the Philosophical Landscape." Informal Logic, XI, p. 92.

Broad, C.D. (1952). "Some Reflections on Moral-Sense Theories in Ethics," in Wilfrid Sellars and John Hospers, eds., Readings in Ethical Theory. New York: Appleton-Century-Crofts, Inc. Reprinted from Proceedings of the Aristotelian Society, 45 (1944-45).

Fearnside, W. Ward and Holther, William B. (1959). Fallacy: The Counterfeit of Argument Englewood Cliffs, NJ: Prentice-Hall, Inc.

Freeman, James B. (1993). Thinking Logically: Basic Concepts for Reasoning. Second Edition. Englewood Cliffs, NJ: Prentice Hall.

Freeman, James B. (1994). "The Place of Informal Logic in Logic," in Ralph H. Johnson and J. Anthony Blair, eds., New Essays in Informal Logic, pp. 36-49. Windsor, Ontario, Canada: Informal Logic.

Gettier, E. (1963). "Is Justified True Belief Knowledge?" Analysis 23, pp. 121-23.

Johnson, Ralph H. and Blair, J. Anthony. (1977), Logical Self-Defense. First Edition. Toronto: McGraw-Hill Ryerson. 
Kahane, Howard. (1980). Logic and Contemporary Rhetoric. Third Edition. Belmont, CA: Wadsworth Publishing Company.

Kornblith, Hilary. (1993). Inductive Inference and Its Natural Ground: An Essay in Naturalistic Epistemology. Cambridge, MA: The MIT Press,

Plantinga, Alvin. (1993a). Warrant: The Current Debate. New York: Oxford University Press. Plantinga, Alvin. (1993b). Warrant and Proper Function. New York: Oxford University Press. Reid, Thomas. (1983). Essays on the Intellectual Powers of Man in Thomas Reid's Inquiry and Essays, Ronald E. Beanblossom and Keith Lehrer., eds. Indianapolis: Hackett Publishing Company, Inc.

Ross, W.D. (1930). The Right and the Good. Cambridge: Oxford University Press.

Seigel, Harvey. (1985). "Educating Reason: Critical Thinking, Informal Logic and the Philosophy of Education." Informal Logic, VII, pp. 69-8I.

James B. Freeman Department of Philosophy Hunter College, City University New York 695 Park Aveme New York, NY 10021 